\title{
Visuospatial Abilities Training with Digital Games in a Primary School
}

\author{
Laura Freina $^{1}$, Rosa Bottino ${ }^{1}$, Lucia Ferlino ${ }^{1}$ \\ ${ }^{1}$ Italian National Research Centre -Institute for Educational Technologies \\ \{freina, bottino,ferlino\}@itd.cnr.it
}

\begin{abstract}
The "A me gli occhi" project was organized to support the development and consolidation of visuospatial abilities in students of the last two years of the Italian primary school, with the hypothesis that such a training would have a positive impact on their performance in mathematics. Twenty game based training sessions were set up along the whole school year, involving two experimental classes, while another two classes served as control group. Students' mathematical abilities were measured at the beginning of the project and at the end using a math test that had been standardized on the Italian population. Results show a statistically significant improvement in the experimental group when compared to the control one for nearly all the indicators considered, confirming the initial hypothesis.
\end{abstract}

Keywords: Visuospatial abilities, STEM primary education, Digital games in Education;

\section{Introduction}

Several studies have demonstrated that there is a strong correlation between visuospatial abilities and school performances in Science, Technology, Engineering, and Mathematics (STEM) [1]; people who have good visuospatial abilities are also more likely to engage in STEM studies and later in STEM related jobs [2, 3, 4]. Children's visuospatial memory seems to have a positive influence on learning mathematics [5], and this influence becomes more important in the last years of primary school (age 9-11) and in the lower secondary school (age 11-14). There are great individual differences in visuospatial abilities; nevertheless, these abilities can be trained with long lasting improvements [6]. According to Newcombe and Frick [7], early interventions to integrate spatial contents into formal education may also reduce differences related to gender and socioeconomic status that may limit a full participation in our technological society. They report research studies that suggest that spatial transformation skills continue to develop through early childhood, so interventions across a range of ages may have a significant impact on children's cognitive development.

This paper describes "A me gli occhi" ("Eyes on Me"), a project aimed at improving primary students' performance in mathematics through training their visuospatial abilities by means of games, mainly digital off-the-shelf entertainment games. This project stems from previous in-field research studies carried out by a group of researchers of ITD (Institute of Educational Technology of the Italian National Research Council) with the aim of investigating the role digital games can have in stimulating and assessing primary school students' logical and reasoning skills $[8,9]$.

This project has already been described by Freina et al. [10] where a preliminary analysis of the collected data was reported. The present paper focuses on a deeper and complete analysis of such data with the additional analysis of data coming from a standardized Italian national test that all students perform at the end of primary school (INVALSI test [11]). In the following, after a brief introduction of "visuospatial 
abilities", the "A me gli occhi" project is described. Then the project outcomes are described along with an accurate report of the data analysis. In the conclusions, some ideas for future research are outlined.

\section{Visuospatial Abilities and Digital Games}

As reported by Bednarz and Lee [12], there is not a unique and globally accepted definition of visuospatial abilities; nevertheless, most researchers agree to include in such a definition spatial visualization (the ability to mentally represent and operate on visual stimuli), spatial orientation (the ability to picture spatially arrayed elements from different perspectives), and the understanding of spatial relations (spatial distributions, locations, imagine maps from verbal descriptions and in general work with maps). Furthermore, visual working memory also plays a key role in visuospatial abilities [5, 13].

There is an extensive body of research that has accumulated over the past twenty years, which consistently shows a correlation between visuospatial abilities and success in mathematics and science. For example, Newcombe [7] reports several different longitudinal studies that started back in the fifties and followed the development of a large number of American children from nursery school to adulthood. These studies have shown that there is a strong correlation between visuospatial abilities and results in STEM areas.

Research has shown that visuospatial abilities can be improved with practice and that such an improvement has long-term effects on student learning [3]. Furthermore, the development of these abilities lasts for many years, starting with infants and continuing through childhood and adolescence. Motor activities, especially at preschool level, may positively affect young children's visuospatial abilities: active movement allows them to link action and cognition, keeping track of the environment during movement and tracking objects during their manipulation [7].

At older ages children can be involved also in progressively more symbolic activities through digital game play. Primary school offers a suitable context at this regard [14]. As the matter of fact, time and curricula constraints and organization are more flexible at this school level than in the following ones, thus providing the opportunity to introduce more easily non-traditional activities. Therefore it seems to be the best time to begin to enhance children visuospatial abilities, contributing to the improvement of their mathematical skills and, consequently, preventing their future failure in this discipline.

The ability to manipulate quickly and efficiently the spatial properties of objects and the spatial relations among them is a key skill in today's world, which is increasingly demanding from a visual point of view, relying more and more on core graphic representations rather than text-based representations. For example, as Mulligan [15] notices, interfaces are becoming less and less alphanumeric and more visuospatial, requiring people to be proficient in spatial understanding.

Some research studies support the assumption that visuospatial abilities training can be effective using a games-based approach [16]. Actually, the use of games in education can enhance students' motivation and involvement in the activities and can help in keeping their attention high $[17,18]$. This causes the students to put a greater effort in the given tasks and, therefore, increase significantly the foreseen advantages. Moreover, experiences that we have conducted since many years have highlighted the high potential of digital games to develop and strengthen reasoning and visual skills and have shown the positive impact of their use on school performance [19]. 


\section{The "A me gli occhi" Project}

Even if it is widely accepted that visuospatial abilities have a direct impact on school performance, there appears not to be enough attention to the development of these abilities in formal education [20]. The "A me gli occhi" project was therefore set up in order to verify if a direct intervention at an early school age would actually have a positive influence on mathematics outcomes.

A specific training was organized with the aim of improving and consolidating visuospatial abilities, as well as exercising the visuospatial working memory in children in the last years of primary school (age 9-11). The hypothesis underlying the project was that training visuospatial abilities of young students for a period of time that was not too short would have a positive impact on their school performance in math. The approach that was selected for the training sessions is based mostly on the use of digital games.

\subsection{Aim of the Project}

The project main aim was to verify if a specific training of visuospatial abilities could have a positive impact on primary school students' mathematics performance. In our hypothesis, visuospatial abilities should have got better with training and, therefore, school results in mathematics should have improved.

\subsection{Target Population}

The age of the target population was accurately selected. According to Meyer's experiment [21], starting from around the age of 8, the visuospatial representations in the working memory play an increasingly important role in predicting mathematical reasoning and numerical operations achievements, while in younger children these abilities are more related to language proficiencies. Furthermore, several studies seem to indicate that visuospatial abilities complete their development around the age of $8[22,23$, 24]. It was therefore decided to address primary students from grades 4 and 5 (aged 9-11) in the project.

Four classes from the local primary school "Cantore" in Genova (Italy), took part in the project. All the students of each class were involved. The experimental group included 38 students, 23 of which from a grade 4 class and 15 from a grade 5 class. The control group included 41 students, 25 from a grade 4 class and 16 from a grade 5 class. All the students were between age 9 and 11. Even if different classes had different teachers, they all followed the same program and regular meetings were organized along the school year, involving all the teachers in the school, to guarantee teaching homogeneity.

All training sessions took place at the school premises during school hours as part of the normal activities. Parents and students had been informed before the start of the project.

\subsection{Research Method}

A quasi-experimental research was set up with the experimental and the control group of participants. It was not possible to randomly assign participants to the two groups since classes could not be divided. A pre-test and a post-test measuring the students' performance in math were collected from both groups. Twenty game based training sessions were organized with the experimental group in the period between November 2016 and May 2017 (one session a week), while the control group just followed the traditional school activities. 
pag. 26

\subsection{Pre and Post Test}

The "AC-MT 6-11", a standardized math test for the Italian primary school was selected for the project [25]. The test is standardized for each primary grade both at the beginning of the school year and at the end. There are different versions of the test for each school grade, all organized into five different sections. Scores for each section were kept separated in the data analysis because the test does not give an overall evaluation and each part of the test involves different abilities.

All the participating classes took the tests both in November (pre-test) and in May (post-test). Class teachers managed them as normal school tests. Scores from the pre-test and the post-test are discussed in the "Data analysis" chapter.

In the following the different sections of the math test used in the project are briefly described.

- Written number operations. This section was made of eight operations, including sums, differences, multiplications and divisions. Each operation was worth one point, for a maximum score of 8 .

- Identifying the biggest between two numbers with decimals. The section involved the comparison between six pairs of numbers for a maximum score of 6 .

- Deducing a number from word names using the place value rules. This section included six exercises, for a maximum score of 6 .

- Ordering numbers with decimals. This task included 10 exercises. The first five exercises asked to order four numbers from the smallest to the biggest, while the following five asked the other way round. The maximum possible score was 10 .

- Word problems. The session on word problems included five problems, four of which needed a twostep reasoning process to be solved, while the other one was simpler and needed only one. The overall maximum score was 9 .

\subsection{Training of the Visuospatial Abilities}

The training sessions were organized once a week, always with the presence of a researcher and a prospective teacher (two senior student teachers involved in the project were present during all the training sessions as part of their apprenticeship). During the training, the researcher worked with half of the class (groups of 8-12 students) for 45 minutes per group, while the rest of the students continued class activities with the teacher, at the end of the period the groups swapped. Each student worked individually with an Android tablet. The training sessions included several different activities: playing with digital games, a Minecraft contest and some gaming activities not based on digital games.

\subsubsection{Digital off-the-shelf games}

Several game apps and computer games were accurately chosen according to their characteristics in order to focus on the training of visuospatial abilities. At each meeting, students played freely, choosing between a restricted set of games focused each time on a specific ability. The games were mainly of the following types:

- Visual memory games (see Figure 1), which included activities like remembering a list of objects, an ordered sequence of elements, the location of items on a $2 \mathrm{D}$ board, etc.

- Movement and rotation of 2D objects by playing traditional games like jigsaw puzzles, tangram, etc.

- Definition of a path on a 2D plane by playing several maze based games.

- Axial symmetry in games in which an image or a solid had to be reflected as on a mirror.

- Movement and rotation of 3D objects using games in which the player had to 
follow a path in a 3D structure. The interface of the games allowed to turn around the structure and to analyse it from different perspectives.

- Spatial Perspective Taking (SPT: the ability to predict what a scene would look like from a different perspective) using the game "In Your Eyes" [26].

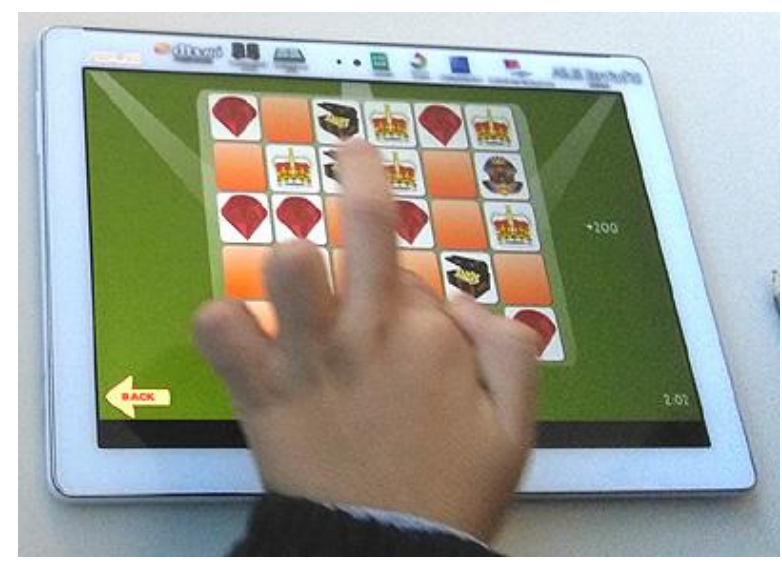

Figure 1. An example of a screenshot of a Visual Memory game

\subsubsection{Other gaming activities not based on digital games}

During the project, some activities that were not strictly or exclusively based on digital games were also organized. In the following these activities are briefly presented.

A virtual Origami game was chosen for the training since origami is a perfect activity to develop visuospatial abilities in that it forces the student to understand how to fold a flat surface into a 3D object, building, while doing so, a mental understanding of the object. The students' reactions to the use of virtual Origami games were not so good: they demonstrated to need to "feel" the 3D object they were building with paper in their hands. Therefore, a session was devoted to building the figures out of real paper while following instructions on the tablet.

Addressing the SPT skills, the "In Your Eyes" game was used. The game, which takes place in a virtual room, asks the player to choose the photo of a table showing it from a point of view from the player's own [26]. The game is available in three different versions: in a completely virtual reality setup [27] with Oculus Rift, in a computer based version, and setting up the game with real objects in the classroom environment. This choice was due to the fact that different environments where to enact the SPT skill may give the students different stimuli, favouring their interest and attention, while helping them to have a full command of the underlying skills. Furthermore, the SPT skills were addressed also with a "photo activity": students were given a picture of the room where they were and they had to move to the place where the picture had been taken from. This task requires the participants to be able to imagine what the room they are in looks like when seen from another point of view.

As an introductory activity to the Minecraft [28] contest (see below), a session was devoted to room plans, which are actually part of the standard school curriculum. Students recognized the plan of a terrace and the location of some items on it, and then they drew the plan of their own classroom. Dealing with plans means understanding a $2 \mathrm{D}$ projection of a 3D space.

\subsubsection{Minecraft contest}

Students were given the plan of a two-floor house with one bedroom, a living room, a bookshelf, and a balcony. The plan was manually sketched on paper. Students were free to build the house using the Android version of Minecraft according to the instructions, adding any further element to their wish, as long as they kept the basic items. Only those projects showing houses with the characteristics defined by the original project were 
pag. 28

admitted to the finals. The finalists had then been voted by the students of the other experimental class and a little prize was given to the winners.

\section{Data Analysis}

The collected data were analysed at first by comparing results from the pre-test and the post-test. Results from this first analysis have been reported by Freina et al. [10]. They show that there is an improvement in the Experimental group in some areas of the test.

A second analysis was then performed: data collected at the pre-test and post-test both from the control and the experimental group were compared to the national averages. The "AC-MT 6-11" test [25] was chosen because normative data are given with respect to the Italian population. Normative data had been computed on a large number of Italian students, with respect to the grade and time of the year (i.e. beginning of the school year vs. the end).

Test instructions were followed to compute the data to be compared and analysed. For each participant, the following indexes were considered:

- The score related to the Written Operations section;

- A score related to "Numeric Knowledge" was computed by adding scores from the sections "Identifying the biggest between two numbers", "Deducing a number from words" and "Ordering numbers from the smallest to the biggest and the other way around;

- The score in Word Problems.

In order to compare each individual score with the normative data, a z-score was computed for each subject, at the pre-test and at the post-test for each indicator, using the normative means and standard deviations. The z-score is a measure of how many standard deviations below or above the population mean each score is, and it can be computed as follows:

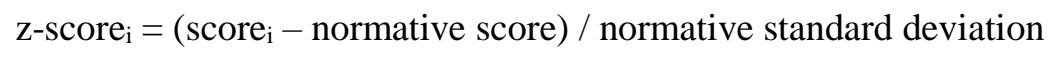

For example, student 4E02 has a Written Operations score of 5 and the normative score in this indicator for his grade is 6.24 with a normative standard deviation of 1.63 , his z-score will be:

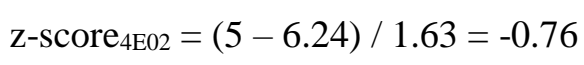

The same procedure was repeated for each participant and for each indicator with reference to the pre-test and the post-test.

Since the aim of the experiment was to measure the impact of the visuospatial training on results at the math test, data were simplified further by computing, for each indicator, the difference between the newly computed $\mathrm{z}$-scores at the post-test and the one at the pre-test. In other words, for each indicator, a single score for each participant has been considered, representing how much closer to (or farther from) the norm their score was in the post-test, compared to the pre-test.

For each indicator, a repeated measures factorial ANOVA was performed, in which the z-score difference between post- and pre-test was predicted by the experimental condition (experimental group vs. control group), the participant's grade (grade 4 vs. grade 5), and the interaction between the two.

In the following, each indicator will be analysed separately.

\subsection{Written Operations}

Table 1 shows the average $\mathrm{z}$-scores and standard deviation for all the groups for the Written Operations indicator. Figure 2 shows the average difference of the z-scores for 
each group, where the $\mathrm{x}$-axis represents the normative scores, and for each group the average change in performance between the pre-test and the post-test is represented.

Table 1. Written Operations. For each group, the sample size, the average zscore and the standard deviation of the z-scores is reported.

\begin{tabular}{|c|c|c|c|c|c|c|c|}
\cline { 3 - 8 } \multicolumn{2}{c|}{} & \multicolumn{3}{c|}{ Pre-test } & \multicolumn{3}{c|}{ Post-test } \\
\hline Grade & Group & No & $\begin{array}{c}\text { Average } \\
\text { z-score }\end{array}$ & SD & No & $\begin{array}{c}\text { Average } \\
\text { z-score }\end{array}$ & SD \\
\hline 4 & Control & 25 & $-0,09$ & 1,11 & 23 & 0,12 & 0,81 \\
\hline 4 & Experimental & 23 & 0,05 & 1,12 & 23 & 0,03 & 1,01 \\
\hline 5 & Control & 16 & 0,04 & 0,75 & 18 & $-0,64$ & 1,55 \\
\hline 5 & Experimental & 15 & $-0,92$ & 1,79 & 15 & 0,00 & 1,09 \\
\hline
\end{tabular}

For the Written Operations indicator, a significant effect for the interaction between experimental condition and grade $(F(1)=8.47, p=.005)$ was found. Post-hoc tests evidence that the experimental grade 5 performed significantly better that the corresponding control grade 5, while all other differences are non-significant. Neither the direct effect for grade $(F(1)=-0.83, p=.364)$, nor the one for experimental condition $(F(1)=1.16, p=.284)$ were statistically significant.

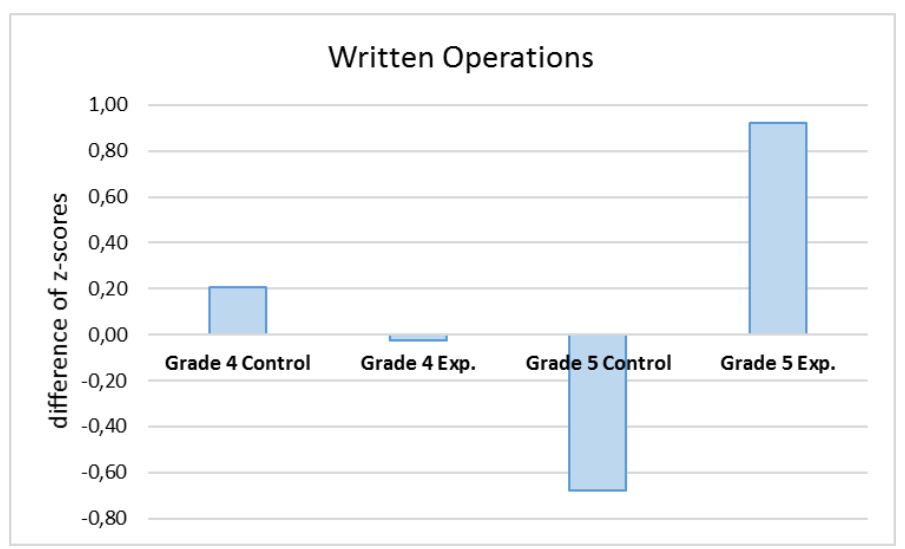

Figure 2. Written Operations. Difference of the average $z$-score at the post-test and the average z-score at the pre-test.

\subsection{Numeric Knowledge}

Table 2 shows the average z-scores and standard deviation for all the groups for the Numeric Knowledge indicator, including the normative data from the test. Figure 3 shows the average difference of the $\mathrm{z}$-scores form each group, where the $\mathrm{x}$-axis represents the normative scores, and for each group the average change in performance between the pretest and the post-test is represented. 
Table 2. Numeric Knowledge. For each group, the sample size, the average zscore and the standard deviation of the z-scores is reported.

\begin{tabular}{|c|c|c|c|c|c|c|c|}
\cline { 3 - 8 } \multicolumn{2}{c|}{} & \multicolumn{3}{c|}{ Pre-test } & \multicolumn{3}{c|}{ Post-test } \\
\hline Grade & Group & No & $\begin{array}{c}\text { Average } \\
\text { z-score }\end{array}$ & SD & No & $\begin{array}{c}\text { Average } \\
\text { z-score }\end{array}$ & SD \\
\hline 4 & Control & 25 & $-0,49$ & 0,99 & 23 & $-0,45$ & 1,54 \\
\hline 4 & Experimental & 23 & $-0,45$ & 1,10 & 23 & 0,16 & 0,63 \\
\hline 5 & Control & 16 & $-0,54$ & 0,73 & 18 & $-0,89$ & 1,71 \\
\hline 5 & Experimental & 15 & $-0,77$ & 1,31 & 15 & 0,01 & 0,91 \\
\hline
\end{tabular}

For the Numeric Knowledge indicator, the ANOVA analysis shows a significant effect of the experimental condition $(F(1)=6.99, p=.010)$ : the experimental group has increased significantly their score at the post-test, both in grade 4 and grade 5 , while it is not so for the control group. No significant effect was found for grade $(F(1)=0.01, p=.916)$ nor for the interaction between the experimental condition and grade $(F(1)=0.43, p=.512)$.

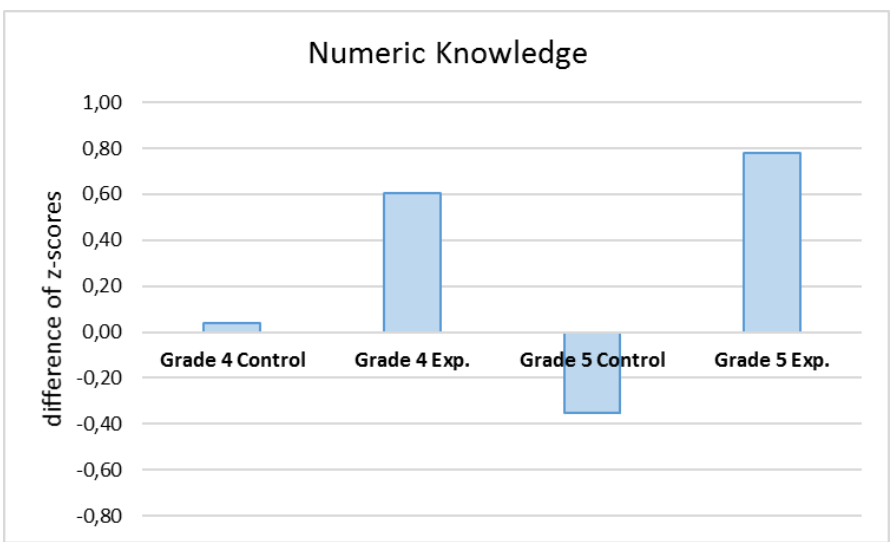

Figure 3. Numeric Knowledge. Difference of the average $z$-score at the post-test and the average $z$-score at the pre-test

\subsection{Word Problems}

Table 3 shows the average $\mathrm{z}$-scores and standard deviation for all the groups for Word Problems, including the normative data from the test. Figure 4 shows the average difference of the z-scores form each group, where the $\mathrm{x}$-axis represents the normative scores, and for each group the average change in performance between the pre-test and the post-test is represented.

Table 3. Word Problems. For each group, the sample size, the average z-score and the standard deviation of the z-scores is reported.

\begin{tabular}{|c|c|c|c|c|c|c|c|}
\cline { 3 - 8 } \multicolumn{2}{c|}{} & \multicolumn{3}{c|}{ Pre-test } & \multicolumn{3}{c|}{ Post-test } \\
\hline Grade & Group & No & $\begin{array}{c}\text { Average } \\
\text { z-score }\end{array}$ & SD & No & $\begin{array}{c}\text { Average } \\
\text { z-score }\end{array}$ & SD \\
\hline 4 & Control & 25 & $-0,42$ & 1,07 & 23 & $-0,98$ & 1,22 \\
\hline 4 & Experimental & 23 & $-0,63$ & 1,14 & 23 & $-0,36$ & 1,33 \\
\hline 5 & Control & 16 & $-0,18$ & 1,13 & 18 & $-0,50$ & 1,23 \\
\hline 5 & Experimental & 15 & $-1,04$ & 0,66 & 15 & $-0,23$ & 1,31 \\
\hline
\end{tabular}


For the Written Problems indicator, again, a significant effect comes from the experimental condition $(F(1)=11.03, p=.001)$ with the experimental group performing better than the control one. No significant effect was found for grade $(F(1)=3.40, p=.069)$ nor the interaction between grade and experimental condition $(F(1)=0.07, p=.794)$.

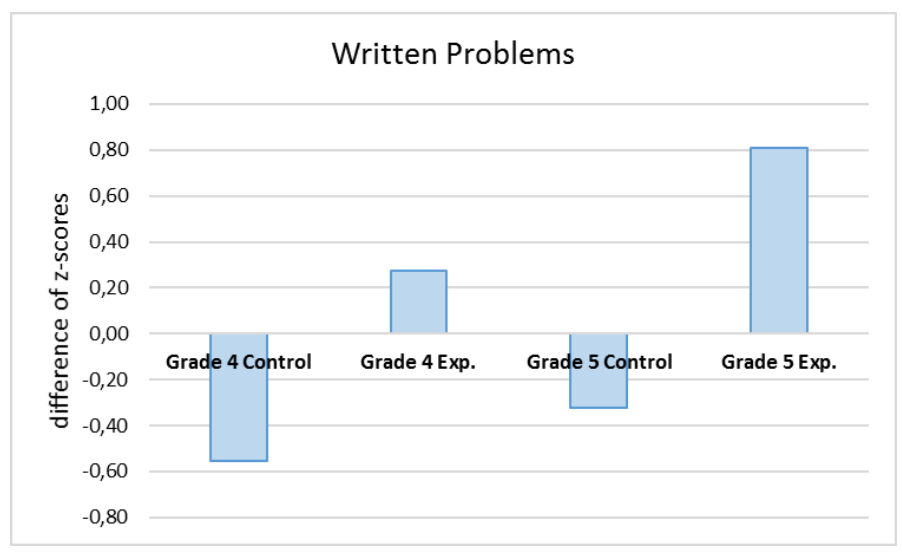

Figure 4. Written Problems. Difference of the average z-score at the posttest and the average z-score at the pre-test.

\subsection{A further indicator for grades 5 only}

One further analysis was done by comparing the scores that the two grade 5 classes got at the part of the INVALSI test devoted to mathematics [11]. INVALSI (National Assessment Institute for the School System) is a standardized Italian national test which provides a 'benchmark' or model level of education that students need to attain and monitors and evaluates learning at a regional or national scale. It is usually taken in all Italian schools, in the month of May, in grades 2, 5, 8 and 10.

Results from the INVALSI test on mathematics of the two grade 5 classes involved in the project have been compared in order to have a further assessment on their academic level in Mathematics. This was only possible for grades 5 since there are no INVALSI data for grades 4.

INVALSI for mathematics is divided into 7 different sections: four thematic areas (Numbers, Space and Figures, Relations and Functions, Data and Forecasts) and three abilities (Knowing, Solving problems, and Reasoning) and an overall evaluation. The graph in Figure 5 shows the difference between class score and Italian average score for the two classes, the last bar (fully coloured) refers to the overall evaluation. It can be seen that while the control grade 5 class scores lower than the average Italian score, the experimental class scores better in nearly all parts of the test, raising above average in some cases. The overall evaluation is 3 points below average for the experimental class and 10 below for the control class.

The INVALSI results show that the grade 5 experimental class performed better than the corresponding control class at the end of the school year, giving a further evidence that the experimental class has, at the end of the year, managed to reach a better performance in math. 


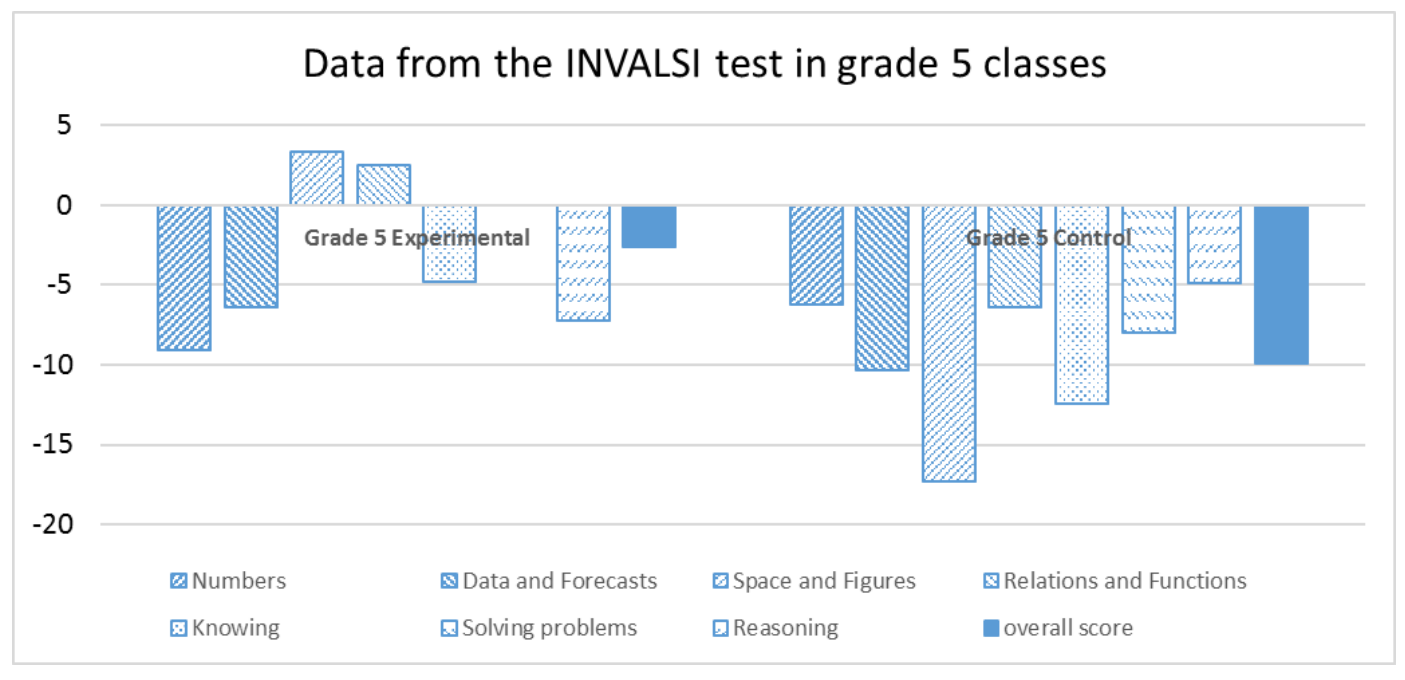

Figure 5. INVALSI test: distance of each grade 5 class from the Italian average score.

\section{Discussion}

In this paper the "A me gli occhi" project has been presented. The main objective of this project was to verify if a specific training of visuospatial abilities, performed mainly with the use of digital games, would have a positive impact on math school results in students from grades 4 and 5 of four classes of an Italian primary school. During the project, twenty game based training sessions were organized, of approximately one hour each, from November 2016 to May 2017. Games were mostly digital apps on an Android tablet, but a computer based game and some concrete gaming activities were also carried out. Each student played individually with one tablet, but peer support was encouraged. A standardized math test was given as a pre-test in November and as a post-test in May to the two experimental classes and the two control classes.

Results from the pre and post-test were analysed by comparing them with the normative data given with the test [25]. Three indicators provided by the chosen test have been considered: Written Operations, Numeric Knowledge and Word Problems. The test used was normalized both at the beginning and at the end of the school year, therefore, the average gain due to the normal school activities should already be taken into account. This allows for a double check:

- First the comparison between the experimental and the control classes who have followed the same curriculum at the same time enhances the gain due to the spatial training only;

- Second the comparison with the normative scores computed at the beginning and at the end of the year gives a clear image of the class level with reference to the Italian population as a whole.

Results show that the experimental classes have managed to increase their scores compared to the normative data significantly more than the control groups with respect to the Numeric Knowledge and Word Problem indicators. Furthermore, this is also true for the grade 5 class in the Written Operation indicator. Results appear to confirm our hypothesis: the improvement of the experimental group along the school year is greater than the average improvement in the Italian population. The INVALSI test for grade 5 classes confirms that the experimental class performs better at the end of the school year than the control one. This is in line with our hypothesis, according to which having good visuospatial abilities has a positive influence on school achievements in mathematics.

The game based training activities, which were carried out in one school year, have involved the researchers working directly with the students. Teachers took part in the 
definition of the intervention, but were not present in the training sessions: classes were divided in two and training was performed with half of the class while the other half worked with the class teachers. Specific guidelines are being defined in order to support teachers in the definition and delivery of similar interventions. This will allow organizing a specific training of the students' visuospatial activities in a more flexible manner, enriching the lessons every time it would be relevant. Future studies, lasting for a longer period, may also consider taking into account a closer monitoring of the students' performance and attitudes.

In all activities, the students' participation and interest was very high. In general, all the suggested activities had been accepted with enthusiasm as confirmed by the data collected from a questionnaires on game enjoyment given to the students at the end of the experiment; nevertheless, some games were liked more than others, as well as some version of the same game were played with more participation than different versions.

The experimenters were rather flexible, offering, at each session, more than one game, always paying attention to maintain the same kind of tasks as far as the visuospatial abilities were concerned. Furthermore, the involvement and interest measured was higher in those games that required a more active participation from the children, as it was the case for the Minecraft contest, Origami, etc. Consequently, a new project has been organized, focusing more on students' creativity, promoting not only game playing but also their creation, following a constructionist approach [29], as was the case for the houses built inside Minecraft during the contest.

\section{Conclusions}

The "A me gli occhi" project started from the hypothesis that a game based training of visuospatial abilities in primary school students would have a positive effect on their school performance in math. The project stems from previous works showing that there is a correlation between visuospatial abilities and results in STEM areas [7]. Actually, Rowrie, Logan and Ramful describe an experiment in which they have found a positive influence of visuospatial training on results in mathematics. In the present experiment, the hypothesis has been pushed a step further, inserting the game element: visuospatial training has been performed through the use of commercially available digital games [16$18]$.

In literature, there still is some disagreement with respect to the impact of playing games on the players' cognitive abilities. In their meta-analysis, Sala, Tatlidil and Gobet [30] report a general lack of skill generalization from one domain to different ones (far transfer), and they find negligible differences between participants who underwent video game training and control groups. Nonetheless, they report a reliable, yet small, correlation between video game skills and spatial abilities. On the other hand, the review from Young, Levine and Mix [31], focused on the relation between spatial and mathematical abilities, reports a strong spatial-mathematical connections and transfer. The "A me gli occhi" project corroborates the existence of at least some transfer: after a specific game based training of their visuospatial abilities, students in the experimental group have managed to increase their scores compared to the normative data of a standardised math test significantly more than the control groups. The initial project hypothesis was confirmed.

Nevertheless, the sample size was rather limited and the class compositions could not be changed, therefore further experiments are needed in order to widen the sample, including schools from different social backgrounds and hopefully better confirming the initial hypothesis.

As far as the participants' enjoyment in the different activities, a very strong interest in the Minecraft contest was noticed: students tend to be more involved in those activities that require them to be more creative As a matter of facts, Minecraft, being a sandbox game [28], involves its users not only as players of a readymade game, but also, in a 
pag. 34

more creative manner, as builders of their own digital experience. According to this result, a new project is now being carried out, in which students in grade 5 are actively making their own visuospatial videogame by means of Scratch programming.

Acknowledgments. The authors would like to thank the school principal Sara Bandini, the class teachers Laura Benedetti and Alessandra De Marco and all the students for their heartfelt participation. The trainee teachers Micòl Arena and Beatrice Crippa for their valuable help working in class with the researcher and their colleague Marcello Passarelli for his help in the statistical analysis of the collected data.

\section{References}

[1] Wing, J. M.: Computational thinking. Communications of the ACM, 49(3), 33-35 (2006). https://doi.org/10.1145/1118178.1118215

[2] Wing, J.: Research Notebook: Computational Thinking - What and Why? The Link. Pittsburgh, PA: Carneige Mellon. (2011).

[3] PNSD:PianoNazionaleScuolaDigitale,

http://www.istruzione.it/scuola_digitale/allegati/Materiali/pnsd-layout-30.10-WEB.pdf, last accessed 2018/06/22.

[4] Bocconi, S., Chioccariello, A., Dettori, G., Ferrari, A., Engelhardt, K. (2016). Developing computational thinking in compulsory education - Implications for policy and practice; EUR $28295 \mathrm{EN}$; https://doi.org/10.2791/792158

[5] Bocconi, S., Chioccariello, A. and Earp, J. (2018). The Nordic approach to introducing Computational Thinking and programming in compulsory education. Report prepared for the Nordic@BETT2018 Steering Group. https://doi.org/10.17471/54007

[6] Román-González, M., Pérez-González, J. C., and Jiménez-Fernández, C. (2017) "Which cognitive abilities underlie computational thinking? Criterion validity of the Computa-tional Thinking Test", Computers in Human Behavior, Vol. 72, pp. 678-691. https://doi.org/10.1016/j.chb.2016.08.047

[7] Kafai, Y. B. Connected Gaming: An Inclusive Perspective for Serious Gaming, The International Journal of Serious Games, Vol. 4, Nr. 3, September 2017 http://dx.doi.org/10.17083/ijsg.v4i3.174

[8] Earp, J., Dagnino, F. M., \& Caponetto, I.: An Italian Pilot Experience in Game Making for Learning. In ICT in Education in Global Context (pp. 171-199). Springer, Singapore. (2016) https://doi.org/10.1007/978-981-10-0373-8 9

[9] Kafai, Y. B.: Playing and making games for learning: Instructionist and constructionist perspectives for game studies. Games and culture, 1(1), 36-40 (2006) https://doi.org/10.1177/1555412005281767

[10] Zaharija, G., Mladenović, S., Boljat, I.: Introducing basic programming concepts to elementary school children. Procedia-social and behavioral sciences, 106, 1576-1584 (2013). https://doi.org/10.1016/j.sbspro.2013.12.178

[11] Bermingham, S., Charlier, N., Dagnino, F., Duggan, J., Earp, J., Kiili, K., ... \& Whitton, N.: Approaches to collaborative game-making for fostering 21st century skills. In European Conference on Games Based Learning, p. 45. Academic Conferences Inter-national Limited (2013).

[12] Bottino, R.M., Ott, M., Tavella, M.: The impact of mind game playing on children's reasoning abilities: reflections from an experience. In Conolly T. and Stansfield M. (eds), Proc 2nd Eur. Conf. on Game-Based learning, Barcelona, Spain, 51-57. Academic Pub-lishing Ltd, Reading, England (2008).

[13] Bottino, R.M., and Ott, M. (2006) "Mind games, reasoning skills, and the primary school curriculum: hints from a field experiment", Learning Media \& Technology, vol. 31, No. 4, 359-375. https://doi.org/10.1080/17439880601022981

[14] Freina, L., Bottino, R., Ferlino, L., and Tavella, M. (2017) "Training of Spatial Abilities with Digital Games: Impact on Mathematics Performance of Primary School Students", Proceedings of the Game and Learning Alliance International Conference (GALA) (December 5-7, 2017, Lisbon, Portugal). 
[15]Freina, L., Bottino, R.: Visuospatial Abilities Training with Digital Games in a Primary School. To be published in International Journal of Serious Games (2018).

[16] Bottino, R.M. \& Chioccariello, A. (2014). Computational Thinking: videogames, educa-tional robotics, and other powerful ideas to think with. KEYCIT - Key Competencies in Informatics and ICT, 184-189. University of Potsdam, Potsdam.

[17] Resnick, M.: All I really need to know (about creative thinking) I learned (by studying how children learn) in kindergarten. In Proceedings of the 6th ACM SIGCHI conference on Creativity \& cognition, pp. 1-6. ACM (2007).

[18] Resnick, M., Maloney, J., Monroy-Hernández, A., Rusk, N., Eastmond, E., Brennan, K., ... \& Kafai, Y.: Scratch: programming for all. Communications of the ACM, 52(11), 60-67 (2009).https://doi.org/10.1145/1592761.1592779

[19] Yin, R.K.: Case study research: Design and methods, Thousands Oaks, Sage (2003).

[20] Pea, R.D.: The Social and Technological Dimensions of Scaffolding and Related Theoret-ical Concepts for Learning, Education, and Human Activity, The Journal of the Learning Sciences, Vol. 13, No. 3, pp. 423-451 (2004). https://doi.org/10.1207/s15327809jls1303 6

[21] Meyer, M. L., Salimpoor, V. N., Wu, S. S., Geary, D. C., \& Menon, V., "Differential contribution of specific working memory components to mathematics achievement in 2 nd and 3rd graders", Learning and Individual Differences, 20(2), 101-109, 2010 https://doi.org/10.1016/j.lindif.2009.08.004

[22] Surtees, A. D. R., Apperly, I. A., \& Samson, D., The use of embodied self-rotation for visual and spatial perspective-taking. Frontiers in human neuroscience, 7, 698, doi:10.3389/fnhum.2013.00698, 2013 https://doi.org/10.3389/fnhum.2013.00698

[23] Piaget, J., and Inhelder, B., The Child's Conception of Space, Trans. F. J. Langdon and J. L. Lunzer. London: Routledge and Kegan Paul, 1956

[24] Newcombe, N., The development of spatial perspective taking. Advances in child development and behavior, 22, 203-247, 1989 https://doi.org/10.1016/S0065-2407(08)60415-2

[25] Ekaputra, G., Lim, C., \& Eng, K. I., Minecraft: A game as an education and scientific learning tool. ISICO 2013, 2013.

[26] Kafai, Y. B., Playing and making games for learning: Instructionist and constructionist perspectives for game studies. Games and culture, 1(1), 36-40, 2006 https://doi.org/10.1177/1555412005281767

[27] Sala, G., Tatlidil, K. S., \& Gobet, F., Video game training does not enhance cognitive ability: A comprehensive meta-analytic investigation. Psychological bulletin, 144(2), 111, 2018 https://doi.org/10.1037/bul0000139

[28] Young, C. J., Levine, S. C., \& Mix, K. S., The connection between spatial and mathematical ability across development. Frontiers in psychology, 9, 2018 https://doi.org/10.3389/fpsyg.2018.00755 